\title{
Familial Hypokalaemic Periodic Paralysis - A Case Report
}

\section{MSH MAJUMDER}

\begin{abstract}
Summary:
Familial hypokalaemic periodic paralysis is a relatively uncommon but potentially life-threatening clinical condition. If recognized and treated appropriately during the episode, patients recover without any clinical sequellae. Reported case presented with recurrent attack of flaccid paralysis of limbs precipitated by carbohydrate meal. Familial periodic paralysis was diagnosed by clinical evidence of flaccid paralysis with positive family history and proved by ECG changes, biochemical findings
\end{abstract}

\section{Introduction}

Hypokalaemic periodic paralysis is an autosomal dominant disorder characterized by acute attacks of muscle weakness concomitant to a drop in blood potassium level ${ }^{1}$. All muscles may involve but cardiac muscle involvement can be a life threatening condition 1,2 . The syndrome of hypokalaemic paralysis represents a heterogeneous group of disorders characterized clinically by hypokalaemia and acute systemic weakness. Most cases are due to familial or primary hypokalaemic periodic paralysis; sporadic cases are associated with many other conditions including barium poisoning, hyperthyroidism, renal disorders, certain endocrinopathies and gastrointestinal potassium losses, especially chronic laxatives abuses. The age of onset, race, family history, medications, and underlying disease states can help in identifying the cause of hypokalaemic paralysis. Initial therapy of the patient with hypokalaemic paralysis includes potassium replacement and search for underlying aetiology. Further management depends on the aetiology of hypokalaemia, severity of symptoms, and duration of the disease ${ }^{1-3}$.

Address of Correspondence: Dr. Md. Shafayet Hasan Majumder, Associate Professor of Medicine, Department of Medicine, Medical College for Women and Hospital, Plot-4, Road-9, Sector1, Uttara Model Town, Dhaka-1230, Bangladesh, Tel: 9665257, 01720172992,E-mail: shafayet57@hotmail.com

Received: 8 May, 2007

Accepted: 26 April, 2009 and hypokalaemia in the absence of other causes of hypokalaemia. The patient improved dramatically with potassium supplementation. Understanding of the illness requires going through recent advances both in electrophysiology and in molecular biology of channelopathies, especially calcium channel structures, functions and genes.

Key words: periodic paralysis, hypokalaemia.

(J Bangladesh Coll Phys Surg 2009; 27: 166-168)

\section{Case Report}

A 35 year old Bangladeshi male with a reasonably good health went to bed following a carbohydrate rich meal at night. While awakening at morning, he noticed that he was unable to move his all four limbs and then he was brought to hospital. Neurological examination revealed flaccid paralysis involving all four limbs with full conscious level and intact sensory system making a diagnosis of Gullein - Berry Syndrome provisionally and lumbar puncture for cerebrospinal fluid study was advised. CSF study was totally normal but blood electrolytes showed severe hypokalaemia turning the diagnosis to hypokalaemic paralysis and E.C.G. showed gross ST segment and T wave changes and the presence of $\mathrm{u}$ waves (Fig. 1). He was euthyroid both clinically and biochemically, normal blood urea and creatinine. He had no swallowing difficulty or urinary retention. He gave no history of vomiting or diarrhea and also no history of chronic laxative abuses. He did not take any diuretic drugs before the illness. He was managed in general ward with potassium replacement therapy to raise blood potassium level both parenterally and orally. His condition started to improve gradually within hours. In the next morning, he recovered fully regaining normal muscle strength and his blood electrolytes and also E.C.G. tracing came to normal limit (Fig. 2). The patient had suffered similar type of attack two years back; and also one of his family member had same type of illness. In his past episode, he was not admitted into hospital, stayed at home and recovered spontaneously after taking rest. We 
explained to the patient about the nature of illness. He was discharged in the next day and resumed his job.

$\begin{array}{lrccc}\text { Serum Sodium } & 143.4 \mathrm{mmol} / \mathrm{L} & \text { Normal } & 135-150 \mathrm{mmol} / \mathrm{L} \\ \text { Serum Potassium } & 1.6 \mathrm{mmol} / \mathrm{L} & \text { Normal } & 3.5-5.5 \mathrm{mmol} / \mathrm{L} \\ \text { Serum Chloride } & 121.4 \mathrm{mmol} / \mathrm{L} & \text { Normal } & 96-105 \mathrm{mmol} / \mathrm{L} \\ \text { Serum TCO2 } & 27.2 \mathrm{mmol} / \mathrm{L} & \text { Normal } & 21-29 \mathrm{mmol} / \mathrm{L}\end{array}$

Fig. 1(a): Serum electrolytes results during the episode

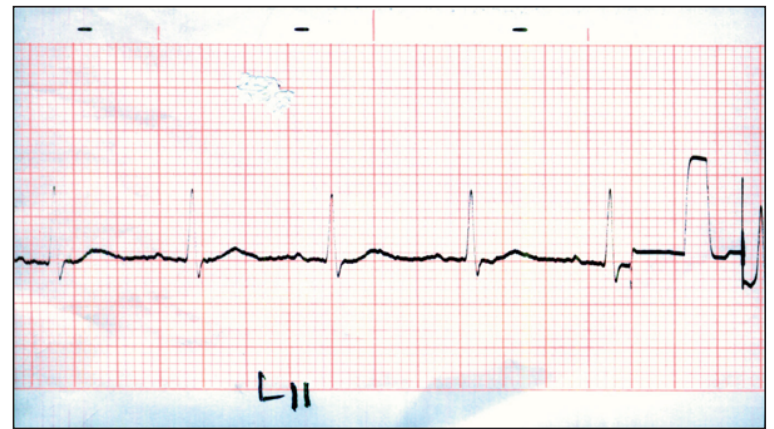

Fig. 1(b): E.C.G. showing ST segment, $T$ wave changes and $u$ wave during the episode.

$\begin{array}{lrcrr}\text { Serum Sodium } & 142.0 \mathrm{mmol} / \mathrm{L} & \text { Normal } & 135-150 \mathrm{mmol} / \mathrm{L} \\ \text { Serum Potassium } & 3.6 \mathrm{mmol} / \mathrm{L} & \text { Normal } & 3.5- & 5.5 \mathrm{mmol} / \mathrm{L} \\ \text { Serum Chloride } & 120.4 \mathrm{mmol} / \mathrm{L} & \text { Normal } & 96-105 \mathrm{mmol} / \mathrm{L} \\ \text { Serum TCO2 } & 26.4 \mathrm{mmol} / \mathrm{L} & \text { Normal } & 21-29 \mathrm{mmol} / \mathrm{L}\end{array}$

Fig. 2(a). Serum electrolytes results after recovery in the next day

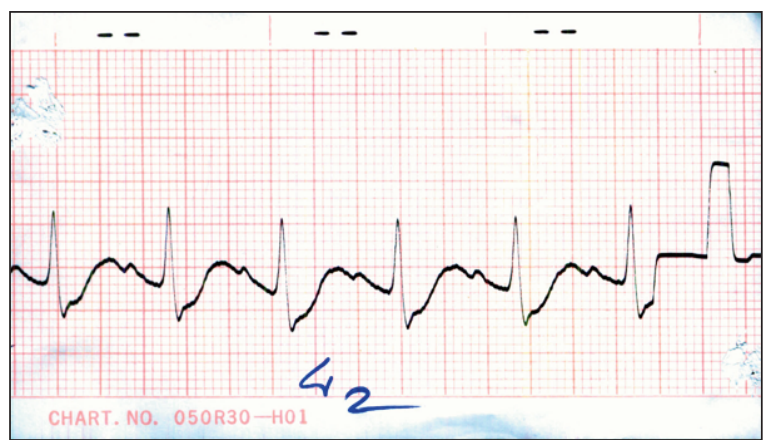

Fig. 2(b). E.C.G. tracing coming to normal limit in the next day

\section{Discussion}

Familial periodic paralyses are caused by functional disturbances of membrane ion channel proteins called channelopathies ${ }^{4,5}$. The channelopathies are a group of disorders caused by mutations in genes encoding ion channels and can affect any tissue, but the majority affect skeletal muscle or the central nervous system ${ }^{6}$.

Channels are macromolecular protein complexes situated in the cell membrane and form pores within their structures. Through these pores, ions flow across the cell membrane and depolarize or hyperpolarize the cell. Channels can be classified into 3 types: nongated, directly gated and second messenger gated channels. Among the important directly gated channels are voltage gated and ligand gated channels. Voltage gated channels include sodium, calcium, potassium and chloride channels; and ligand gated channels include acetylcholine, glutamate, glycine gated channels. The following inherited channelopathies are usually described. (1) Sodium channelopathies: familial generalized epilepsy, hyperkalaemic periodic paralysis; (2) potassium channelopathies: benign infantile epilepsy; (3) calcium channelopathies: familial hemiplegic migraine, hypokalaemic periodic paralysis; (4) chloride channelopathies: myotonia congenita. The macromolecular protein complex of channel is divided into distinct protein units called subunits. Each subunit has a specific function and is encoded by a different gene. More than one gene may regulate a function in a channel, thus different genetic mutations may manifest with the same disorder $4,7,8$.

In hyperkalaemic periodic paralysis, mutant skeletal muscle sodium channels fail to close completely after an action potential. This evokes paralysis caused by hyperpolarisation and inexcitability. In hypokalaemic periodic paralysis, mutation affects the closing of skeletal muscle calcium channels, inducing depolarization block causing transient paresis or paralysis 5,9 .

Serum potassium is normally maintained within a narrow range through an exquisite balance between cellular $\mathrm{K}+$ efflux and influx, and between the intake and output of potassium from the body. Ultimately such balances are determined by cell membrane molecules which effect $\mathrm{K}+$ transfer from one milieu to another. Familial hypokalaemic periodic paralysis is associated with mutations of the dihydropyridine receptor gene encoding the L-type $\mathrm{Ca}+2$ channels, but 
how such mutations result in episodic hypokalaemia and paralysis remains a mystery ${ }^{10,11}$. So, still the difficulty remains how to explain the cause of hypokalaemia which is almost always preceding the attack of periodic paralysis of this type ${ }^{11}$.

Thyrotoxicosis should be ruled out as a cause of periodic paralysis. Thyrotoxic periodic paralysis usually occurs in Asian populations with an incidence of about $1.9 \%$ in thyrotoxic patients. The diagnosis often can be made on the basis of the clinical manifestations alone. Sometimes, periodic paralysis precedes hyperthyroidism or occurs in silent hyperthyroidism 12,13 . In Japan, more than $60 \%$ of hypokalemic periodic paralysis is thyrotoxic instead of familial type ${ }^{9}$. Periodic paralysis is usually provoked by high carbohydrate meal or sodium containing diets or may occur during rest after prolonged exercise. The attacks are episodic and last for $2-12$ hours and frequency of attacks may be daily to yearly. Low serum potassium during attack establishes the diagnosis. Muscle biopsy shows single or multiple centrally placed vacuoles and E.C.G. traces flattening of the $\mathrm{T}$ waves and $\mathrm{ST}$ depression with $\mathrm{u}$ waves; muscle biopsy was not done in the presented case $\mathrm{e}^{2}$. Initially parenteral and latter on oral potassium was given. Administration of potassium in dextrose acqua or dextrose normal saline is avoided as it may further lower the potassium level and manitol is preferred vehicle for intravenous potassium. Long term attacks may be prevented by avoiding carbohydrate, sodium and intense exercise and prophylactic administration of acetazolamide, triamterone or spironolactone ${ }^{2}$. Understanding the pathophysiology of the potassium sensitive periodic paralysis ought to reduce genetic complexity and increase the likelihood of observing true clinical effects. Ideally, therapy for the familial periodic paralysis will prevents attacks, avoid permanent weakness and improve quality of life. Moreover, understanding the skeletal muscle channelopathies will hopefully lead to insights into the more common central nervous system channel diseases such as migraine and epilepsy ${ }^{14}$.

\section{Conclusion}

Periodic paralysis should be considered as a medical emergency because severe hypokalaemia not only cause muscle weakness or paralysis but also may cause fatal cardiac arrhythmia leading to death. Understanding of channelopathies is advancing rapidly. Studies of human inherited channelopathies have clarified the functions of many ion channels. The complex picture of the genetic and molecular structures of channels requires frequent updates.

\section{References}

1. Lapie P, Lory P, Fontaine B. Hypokalaemic periodic paralysis: an autosomal dominant muscle disorder caused by mutations in a voltage gated calcium channel. Neuromuscul Disord. 1997 Jun;7(4):234 - 40.

2. Brown RH, Mendell JR. Muscular dystrophies and other muscular diseases. In: Kasper DL, Fauci AS, Braunwald E, Isselbacher KJ, Wilson JD, Martin JB,et al. Harrison's Principles of Internal Medicine. 16th ed. New York: McGraw-Hill Companies ; 2005 : vol-2, p. 2536-7.

3. Ahlawat SK, Sachdev A. Hypokalaemic paralysis. Postgrad Med J. 1999 Apr ; 75(882) : 193 -7.

4. Lehmann H F, Jurkat RK, Rudel R. Periodic paralysis: understanding channelopathies. Curr Neurol Rep. 2002 Jan ; 2(1) :61-9.

5. Bond EF. Channelopathies: potassium related periodic paralyses and similar disorders. AACN Clin Issues. 2000 May ; 11(2) :261-70.

6. Surtees R. Inherited ion channel disorders. Eur J Pediatr. 2000 Dec; 159 Suppl 3: S199-203.

7. Dworakowska B, Dolowy K. Ion channels-related diseases. Acta Biochim Pol. 2000; 47(3):685-703.

8. Celesia GG. Disorders of membrane channels or channelopathies. Clin Neurophysiol. 2001 Jan; 112(1) :218 .

9. Shishiba Y. Recent progress on the search of pathogenesis of thyrotoxic periodic paralysis. Nippon Rinsho. 2006 Dec; 64(12) : 2339-47.

10. Antes LM, Kujubu DA, Fernandez PC. Hypokalaemia and the pathology of ion transport molecules. Semin Nephrol. 1998 Jan; 18(1) : 31-45.

11. Shishiba Y. Current status of clinical and molecular biological research on familial periodic paralysis. Nippon Rinsho. 1997 Dec; 55(12) : 3239-46.

12. Hsieh CH, Kuo SW, Pei D, Hung YJ, Chyi-Fan S, Wu LI et al. Thyrotoxic periodic paralysis: an overview. Ann Saudi Med. 2004 Nov-Dec; 24(6) : 418-22.

13. Lin SH. Thyrotoxic periodic paralysis. Mayo Clin Proc. 2005 Jan; 80(1) : 99-105

14. Venance SL, Cannon SC, Fialho D, Fontaine B, Hanna MG Ptacek LJ, et al. The primary periodic paralyses: diagnosis, pathogenesis and treatment. Brain. 2006 Jan; 129: 8-17. 